\title{
A Case Study: An Analysis of Organizational Changes of Henan Machinery and Electric Import and Export Corporation
}

\author{
Bing WANG \\ Business English Department, Foreign Languages School of Henan University of Science and \\ Technology, No. 263, Kaiyuan Road, Luoyang, Henan, China \\ wangbinglaoshi@qq.com
}

Keywords: Management, Leadership, Organizational Change, Organizational Environments.

\begin{abstract}
This paper describes change events as a case study in a company called Henan Machinery and Electronic Import and Export Corporation, and analyzes the change events utilizing constructs of organizational environments, structure, leadership and culture, in order to get a better understanding of the change in an organization.
\end{abstract}

\section{Introduction}

In this study, the author tries to first describe and then analyze several organizational changes in the development of a local company by the name of Henan Machinery and Electric Import and Export Corporation. After investigating the target company's developing history, some significant points are found. These points are displayed in this paper as three issues of a) change of personnel in 2006; b) change of government's policies in recent years and c) the financial crisis in 2008. The literature reviewing gives the author a clear vision of how the organizational changes are formed and then implemented. The paper then falls into two parts: the analysis of the causes of organizational changes, in which Senior's theories [1] and Burke-Litwin's casual model [2] are mainly adopted, and the process of the changes, in which Lewin's three-step model [3] and Kotter's eight-step change process [4] are adopted. The conclusions will be made; the implications and the limitations will be discussed after fully analyzing the HMEIEC case.

\section{Brief Introduction of the Change Event}

Henan Machinery and Electric Import and Export Corporation, LTD, which is a subsidiary of China National Machinery \& Equipment Import \& Export Corporation (CMEC), were founded in 1997. The company mainly does business of exporting parts of mechanical equipment with the USA companies. Henan Machinery and Electric Import and Export Corporation, LTD is a half-privatization half-nationalization company. It was a new business model when the company was founded, because almost all the import and export companies were state share-holding. The head of the company are General Manager, who is responsible for the Finance Department and the Deputy General Manager, and the Vice Secretary of the Party Committee, who is also the Chief of Office, in charge of the Party affairs, logistics and administration. The Deputy General Manager is in charge of two Business Departments, in which salesmen are devoted to finding more clients, seeking more business opportunities, exploiting market,and retaining stable sources of customers. In the next ten years, the company had a group of stable clients to ensure further development, and gained considerable profits every year. Fame and good reputation came naturally. During the later development of the MEIEC Company, three notable issues emerged, which will be elaborated in the following paragraphs.

\section{Issue One}

In the year of 2006, the General Manager, who was respected and venerated, left the company because of health problems. The company then promoted a Business Manager to be the General Manager. However, the new manager maintained the traditions and didn't make any change to the 
company. At the same time, a lot of experienced senior management staff retired, including the Deputy General Manager. As those meritorious while aged heroes left, a lot of vacant places had to be filled by less experienced while young and enthusiastic people.

\section{Issue Two}

Recent years, the Chinese government has changed tremendously in her general policy for the importing and exporting market. Since the adoption of policies of reform and opening to the outside world in 1979, the government had been advocating exporting business. But the government made some adjustments on the export tariff, leading to a notable increase of the export product prices, eventually weakened the competitiveness of Chinese export industry and leaving little profit to the exporting companies. Henan Machinery and Electric Import and Export Corporation thus changed its structure in response to the reality. The two Business Departments which used to focus on exporting market both were changed into one on exporting and the other on importing.

\section{Issue Three}

Unfortunately, a world-wide financial crisis broke out in 2008, causing the rise of the price of raw materials and the appreciation of RMB. More importantly, due to the fact that most of the clients are from the center of the 2008 financial crisis, the USA, the bankrupt of many American client companies finally heavily stroke on Henan Machinery and Electric Import and Export Corporation. The profit of the company decreased remarkably. In order to control this decrease, the General Manager reacted rapidly to the disadvantaged situation and made several crucial decisions. Firstly, store up sufficient raw materials before the price raise further. Secondly try to maintain the product prices rather than raise the selling prices with the price of raw materials. Thirdly, settle up bills at the right time according to the exchange rate. Fourthly, avoid risk investment and stop doing business with those less powerful companies. And at last, adjust the encouragement system and reward system. Evidently, the plans worked out, and the company is now expecting a rise in profit.

In this study, I will mainly analyze the causal elements in the three issues, especially the external environment, and the organizational change process, and the process of organizational change utilizing Lewin's three-step procedure of changing and Kotter's eight-step change process.

\section{What Is Organizational Change}

As many books imply, an organization is a group of people working together for certain purpose, in which the role of the person rather than the person himself is emphasized, regardless of the changes of members [5]. A change in an organization, as defined by Dawson, is 'any alteration in activities or tasks'[6], and is likely to happen now and then. The reasons why organizational changes have to take place are closely related to the environment the particular organization is in. Senior [1] distinguished the environment into three types: the temporal environment, the external environment and the internal environment. The first environment has a relatively long-term influence on the organization through the cycle of the industry the organization is in or the life cycle of the organization itself, and I will not explain more about it. The external environment refers to the elements of the outside world which the organization is in, including political, economics, technological and so on. In the case described previously, the change of the government policy and the 2008 financial crisis can be included in the external environment. The internal environment summarizes any changes within the organization, as in the case above, a new General Manager, a new Business Department and new strategies. I will explain more details later in this study. The changes can also be identified as revolutionary (or transformational), meaning a change of deep structure, and evolutionary (or transactional), the attempts to improve performances [7].

\section{Organizational Environments}

As I have mentioned above, the organizational environment are divided into three types: temporal, 
external and internal [1]. I will analyze the first two issues using Senior's theories.

\section{Temporal Environment}

When HMEIEC was founded in 1990s, the model of running an export and import company in sort of private-owned way was definitely an innovation. HMEIEC gained a fine profit, resulting from integrated reasons. The Chinese government advocated and supported trade activities with great efforts when the Chinese market was opened, including gaining a favorable balance in foreign trade, by establishing policies and regulations. In addition to this superiority, other advantages were cheap raw materials and labor power, together with excellent processing techniques. But recent years, the export market has been suffering from a super saturation. As a result, the government is now trying to encourage import trade and restrain export trade. Under this circumstance, HMEIEC incisively took actions and coped with new situation by transforming one former export Business Department to an import one. The business scope was expanded along with new opportunities. The decline of the operating modes and the exporting industry belong to the temporal environment elements.

\section{Internal Environment}

The internal environment is shown in both Issue One and Issue Two. In Issue One, the retirement problem triggered a series of changes among members. The changes of a new General Manager, a new Deputy General Manager, a new Business Manager and several staff would definitely unstabilize the company's overall performances. The new chief's solution was to maintain the old traditions and the old operating practices, aiming at alleviating the unstabilizing factor. In Issue Two, the function of one department changed, directly caused by changes from the outside world. The change of one Export Business Department into an Import Business Department broadened the business market for the company and provided much more opportunities in later development of Henan Machinery and Electric Import and Export Corporation.

\section{External Environment}

Senior introduced PETS (i.e., political factors, economic factors, socio-cultural factors and technological factors) to further explain the external environment changes [1]. The political factors include government legislation, government ideology, international law, universal rights, wars, local regulations, taxation and trades union activities. The economic factors consist of competitors, suppliers, currency exchange rates, employment rates, wage rates, government economic policies, other countries' economic policies, lending policies of financial institutions, and changes from public to private ownership. The socio-cultural factors are listed as demographic trends (customers and employees), lifestyle changes, skills availability, attitudes to work and employment, attitudes to minority groups, gender issues, willingness and ability to move, concern for the environment, and business ethics. And the technological factors contain information technology/the internet, new production processes, computerization of processes, and changes in transport technology [1].

In Issue Two, political factors and economic factors are presented as adjustment of tariff and the change of government exporting policies respectively. The rise of the exporting tariff belongs to the political factors and the change of government policies towards exporting trade market is an economic factor

Haveman, Russo, and Meyer further explained the impact of regulatory change in their study. They concluded that "many regulatory changes are large in magnitude and drive organizations to fundamentally alter their strategies, structures and activities", and "although organizations affected by regulatory punctuations may act purposively, partial foresight and imprecise prediction of their impact generate substantial unintended consequences" [8]. Thus, organizations should be careful with regulatory changes and make wise choices. A model of punctuated evolution was recommended in understanding large-scale regulatory change [8].

When I look back at the environment of Issue Two again, yet as a whole rather separately, I realize that the external environment change and the internal environment change exist in an 
interdependent way [6]. The external changes of tariff and exporting policies caused the reduction of company profit, which then forced the company to find ways to save the company turning to the importing market and made adjustment in department functions. The internal changes in organizations are usually resulting from the external changes, and only by responding rapidly and accurately to the external changes, can the organizations survive in critical moments [1]. Still, in real life, we may also find evidence to prove the other way round, which will not be discussed here.

In a study of corporate responses to crises, Smart and Vertinsky [9] combined the strategies adopted by an organization with the external environment the organization is in, which gives me some enlightenment. In their study, the external environment is conceptualized into two important dimensions: the degree of environmental stability and that of complexity [9]. As organizations should respond to the external environment, the strategic responses were further divided into four branches: long-term entrepreneurial (strategic) responses, entrepreneurial short-term (tactical) responses, short-term adaptive (fire-fighting) responses, and long-term adaptive (planning) responses, each fits for different environments respectively [9]. The strategies adopted are very crucial during the change process, thus managers can't be too careful when making decisions. Just as Kotter and Schlesinger said, "even the most outstanding interpersonal skills will not make up for a poor choice of strategy and tactics" [10].

\section{Burke-Litwin Causal Model of Organizational Performance and Change}

When analyzing the HMEIEC case Issue Three, I would like to use the Burke-Litwin casual model of organization performance and change [2]. In the two-dimensional Burke-Litwin model, twelve variables (listed as external environment, mission and strategy, leadership, culture, structure, management practices, systems, climate, task requirements and individual skills/abilities, individual needs and values, motivation, individual and organizational performance) are connected by arrows going both directions, indicating that any two variables may affect and may be affected by each other (e.g., the external environment may affect the organizational performance through policy and regulation, meanwhile the organizational performance may affect the external environment via products and services). This model also clarifies organizational changes as transformational and transactional. The transformational changes concern with external environment, mission and strategy, leadership, organization culture and individual and organizational performance variables which are more likely caused by environmental forces, while the transactional changes the other variables which are short-term changes through people's reciprocity.

I will then try to figure out some variables in the HMEIEC case to better illustrate the Burke-Litwin model. As is shown in my case, the external environment, defined as any condition or situation outside the organization that may influence the organizational performance, is the financial crisis in 2008, causing the raw materials price rise, the RMB appreciation and client companies' bankrupt. The mission and strategy, meaning the identified main purpose and how to achieve this purpose, are to restrain the profit loss, and the five steps the General Manager adopted. The change in the system of this case is mainly the rewarding system, especially in the allotment of salaries. The salary of staff in the two Business Department both the salesmen and the Business Managers raised while the salary of staff in the Office Department dropped relatively, in order to encourage the salesmen to find more and reliable clients and business. The welfare provided by the company also reduced accordingly when the company couldn't earn enough money. The individual and organizational performance is the fact that the profit increased at last.

In the transformational changes, the actuality of the financial crisis directly determined the company's mission of taking control of the disadvantageous situation and the strategies taken by the General Manager. As the consequence of the strategies taken, the performance of the company's performance improved. In this order, as Burke and Litwin indicated, the former variables have more influence on the latter ones rather than vice versa, which means the former have more 'weight' than the latter. Yet in the transactional changes, the change of the salary allotment system and the welfare measure encouraged the staff to work harder and perform better, meanwhile, the individual and 
organizational performance will on the other hand affect the change of the rewarding system in the way of how much profit the company can make. This phenomenon illustrates that the two variables can affect each other. This case perfectly proves the operationalization of the Burke-Litwin Causal Model of Organizational Performance and Change.

\section{Lewin's Three-Step Model}

Lewin's three-step procedure of changing consists of unfreezing, moving and freezing steps. The unfreezing step is to change the present state of the organization, the moving step is to move from the present state to a new state, and finally the freezing step is to stay at the new state [3].

In the change event of personnel in Issue One, the unfreezing stage is the actuality of the aging senior managing staff. The senior managing staff hadn't been changed for a rather long time since the founding of Henan Machinery and Electric Import and Export Corporation in 1997. In 2006, almost all the senior staff went into their 50s or 60s, and after years of striving, their health problems and their lack of enthusiasm caused troubles in daily work. The retirement of the General Manager pulled the trigger at last. The retirement of the Deputy General Manager was announced not long after the retirement of the General Manager.

The moving stage is the process of arranging new people in the place of old staff. Before the General Manager left the company, the senior managing staff decided to promote a Business Manager, who was much younger, to be in charge of the whole company later. In order to replace the old with the new smoothly, the jobs of inviting applications started just at heels of the staff retirements. Several excellent applicants entered the company after strict interviews.

The freezing stage refers to the adjustment in the younger company. One thing should be noted is, that the Vice Secretary of the Party Committee, who is also the Chief of Office, stayed in the company. His stay played an important role in controlling and stabilizing the affairs and functions of the whole company. In later times, the Vice Secretary of the Party Committee helped and supported the new General Manager to work out strategies when encountering crisis. In fact, the Vice Secretary was regarded as the soul of the company, a leader the staff chose to rely on. Nevertheless, absorbing new people was like to inject fresh blood into the company, making it a more energetic and active organization [7].

\section{Kotter's Eight-Step Change Process}

The settlement of the change event in Issue Three follows the eight steps of Kotter's change process theory. The eight steps are Establishing a Sense of Urgency, Forming a Powerful Guiding Coalition, Creating a Vision, Communicating the Vision, Empowering Others to Act on the Vision, Planning for and Creating Short-Term Wins, Consolidating Improvements and Producing, and Institutionalizing New Approaches [4].

\section{Establishing A Sense of Urgency}

In the first step, the organization should take a close look at the market and competitive realities, in order to identify and discuss real and potential crises, or major opportunities. When doing so, the leaders of the MEIEC realize that the financial crisis was a real crisis in the external environment and needed to be dealt with as soon as possible. Because, the price rise in the raw material market raised the cost of product manufacturing, the appreciation of Chinese currency weakened the advantages of China's export trade in some way, and the bankrupt of client companies left the MEIEC a great loss from previous unpaid business bills.

\section{Forming A Powerful Guiding Coalition}

The second step is to congregate people with enough power to work together and to lead the change effort. Usually, a change effort starts with very few people, and then the group of believers grows gradually. The aim in this phase is to gather the core of believers, people with higher 
reputation, higher status, and good relationship with others, for example. These people then might influence others and help to make others to believe that the change is necessary [11]. In order to discuss the strategies in respond to the crisis, the company gathers all the managers, and the Vice Secretary together to form a powerful coalition.

\section{Creating A Vision}

The third step is to create a vision for making changes and work out strategies for conducting the change. The guiding coalition figured out the three main crises the company was faced with, and drew up corresponding strategies afterwards, including storing up raw materials before the price raise further; maintain the product prices; settling up bills at the right time; avoiding risk investment and adjusting the reward system. The leader must have a clear picture in mind of directions the company goes in and the future of the company.

\section{Communicating the Vision}

Forth, communicate with other organization members about the vision. Only when the company staff understand, accept and appreciate the change effort, can the change be successfully made. The guiding coalition of MEIEC gathered the whole company staff to inform others of the present conditions of the company, thus get all of the company prepared for confronting the crisis.

\section{Empowering Others to Act on the Vision}

Fifth, take actions and conduct the changes to empower others to act on the vision. In the MEIEC case, the leaders firstly changed the way of manufacturing, because the company used to buy raw materials only when business was fixed. The second change took place in clients group. The MEIEC Company trusts clients very much, and even accepts the clients' delaying payment, only to build a harmonious and trustworthy friendship. Since some of the clients were badly influenced in the financial crisis, the company decided to check carefully on previous business and became cautious in the payment of clients. The third change was more and more attention was payed on the Import Business Department's performance. Even though the Import Department was established before the financial crisis, the Export Department maintained its vital position in the company. However, the Export Department got severely hit; the expectation for prospering the company was naturally diverted from the Export Department to the Import Department.

\section{Planning for and Creating Short-Term Wins}

The sixth step can be interpreted as 'planning for and creating short-term wins by publicizing success, thereby building momentum for continued change' [12]. People rarely stick to a change for long enough time without actually seeing the value. Things would be better if evidence of achievement can be shown short after their effort. Shortly after the actions listed above were taken, the staff was gathered again to sum up the achievement during this period of time. In the 2008 financial crisis, the two Business Departments were considered as the life of the company, the executives made a proposal of changing the rewarding system which would be in favor of the salesmen rather than the other office staff, so that the salesmen could be encouraged to seek more business opportunities.

\section{Consolidating Improvements and Producing}

Seventh, evaluate, understand and then make more changes to systems, structures and policies that do not agree with the vision. It might take a rather long time to prove whether a new change is successful. As a consequence, the manager should be patient, and should take a good look at the change and make proper adjustments to it, to ensure its success. The profit of the company was fairly improved after the changes. All the efforts made seem to be appropriate except for the treatment adjustment towards the clients. Some clients felt unsatisfied with the icy manner. So the leaders determined to change a little to a bit more friendly manner, but the clients' ability of 
affording the payment should be assessed and assured before starting to do business with. And in the short term, the company refused to do risk investment.

\section{Institutionalizing New Approaches}

In the end, connect the change to organizational success and institutionalize the new approaches. After trying out the new rewarding system, the performance of the company progressed pretty much, this new system was adopted officially. In the new rewarding system, the salary a salesman can get is directly associated with how much money he/she has made for the company, not as in the past, partly determined by the average level of the salary. Although the percentage of the office staff's salaries dropped relatively, the salesmen made more profit for the company, allowing the office staff getting more money actually. Only when the change becomes a real part of the company, can the change be judged as successful.

Some obstacles also occurred during the change, as it is normal that human resistance exists when organizational changes are taken place. The most common reasons for human resistances include, as Kotter and Schlesinger have summarized, a fear of losing something of value, a misunderstanding of the change itself, a belief of unnecessity of the change, and a low tolerance of the change [10]. The managers should be quite aware of these reasons and should take measures to deal with the resistances. As in the case being discussed, when the thought of changing the reward system was firstly brought about, the guiding coalition should realize that the drop of the Office Department staff's salary might arouse fierce dissatisfaction among the staff. And this did cause some troubles in the company. The Office staff always complained about this problem and sometimes they even chose not to cooperate with the managers. The conflict came into being between the Office Department and the Business Department. The Business Department staff insisted that unlike the Office staff, who sat all day in the comfortable office dealing with paper work only, they themselves were much busier and took much more responsibilities in the company. The Office Department staff argued that everyone was important as others; any policy in the company should be equal with everyone, and obviously, raising some people's salary while reducing the others' was unfair, especially when they were equally hard-working. The principle contradiction lies in the fear of losing something of value. Kotter and Schlesinger also suggested ways of solution, listing as education \& communication, participation \& involvement, facilitation \& support, negotiation \& agreement, manipulation \& co-operation, and explicit \& implicit coercion (2008). Direct communication, emotional support, peaceful negotiation and necessary coercion were main measures taken in the case. Dissatisfaction effectively reduced, however complaints still came out now and then.

\section{Conclusion}

In this study, the author describes the case of a local company called Henan Machinery and Electric Import and Export Corporation, and three outstanding change events emerged during its development. The three issues are the change of personnel resulting from aging problem, the internal change caused by the change of government policy in the external environment, and the 2008 financial crisis leading to corresponding changes in the company.

The author then adopted Senior's organizational environment theories [1] to analyze the temporal, external and internal environment in the first two issues; Burke-Litwin's Causal Model of Organizational Performance and Change [2] to identify different causal elements in the third issue. Two models of change process are also used in the study to illustrate the phases in implementing changes of the case. Lewin's three-step model [3] was used in analyzing the change event described in Issue One, and the Kotter's eight-step change process model [4] was introduced in the analysis of Issue Three.

After applying the theories to thee real case, conclusions can be made as follows. The organizational environment is decisive in organizational changes and the external environment may cause the internal changes directly. The causes of organizational changes can be divided into 
transformational and transactional. The process of organizational changes follows certain patterns. When a crisis or a change happened no matter inside the company or in the outside world, the leaders of Henan Machinery and Electric Import and Export Corporation were able to be aware of what the situations were, and were able to evaluate them. They could then calmly figure out strategic decisions to help the company through disadvantageous circumstances. All these implicate that changes in an organization and in the outside environment are inevitable. Managers in the organization should be alert and should possess the capability of judging and evaluating. Before making strategies, a good manager needs to analyze the present situation, problem and the forces of the problem, and analyze the factors concerning with producing the change as well. On the basis of these analyses, the strategies then can be made as detailed as possible and should be internally consistent. Finally, the manager must carefully monitor the implementation, and be prepared for anything unexpected to happen, and make proper adjustment during the process of the change [10]. The major limitation of this study is that the theories are only used to analyze the phenomenon, but not be used as instructions.

\section{References}

[1] B. Senior, Organizational Change, England: Pearson Education Limited, England, 1997.

[2] W. Burke, G. Litwin, A causal model of organizational performance and change. Journal of Management, 18(1992) 523-545.

[3] K. Lewin, Group Decisions and Social Change. In G.E. , Swanson, 1958.

[4] J. Kotter, Leading change: Why transformation efforts fail. Harvard Business Review, 73 (1995) 9-67.

[5] D. Statt, Concise Dictionary of Business Management, Routledge, London, 1991.

[6] P. Dawson, Organizational Change: A Processual Approach, Paul Chanpman Publishing Ltd, London, 1994.

[7] W. Burke, Organization Change Theory and Practice, Sage Publications, Inc, USA, 2008.

[8] H. Haveman, , M. Russo, A. Meyer, Organization science, 12 (2001) 253-293.

[9] C. Smart, I. Vertinsky. Strategy and environment: a study of corporate responses to crises. Strategic Management Journal, 5 (1984) 199-213.

[10] J. Kotter, L. Schlesinger, Choosing Strategies for change. Harvard Business Review, March-April (1979) 106-114.

[11] J. Kotter, Leading change, Harvard Business School Press, USA, 1996.

[12] A. Armenakis, A. Bedeian, Organizational change: a review of theory and research in the 1990s, Journal of Management, 25 (1999) 293-315. 